1972). Further studies, particularly serial totals in individual patients, should clarify this point.

In patients who are uncertain of their menstrual dates and in whom postmaturity may be feared we have preferred to assess the pulmonary maturity by lecithin estimations in preference to other methods of estimating fetal gestation. Though liquor volume, and hence total lecithin content per fetal sac, seems to be unimportant to the prognostic reliability of lecithin concentration in most cases, the evidence suggests that it is important in borderline cases where the lecithin concentration is around $3.5 \mathrm{ml} / 100 \mathrm{ml}$ and a decision has to be made on whether to deliver. If total lecithin in the sac is to be used as the parameter it would seem from our preliminary series that levels below $20 \mathrm{mg}$ per sac indicate that the fetus would be at risk if delivered.

We wish to thank the consultant obstetricians at Saint Mary's Hospital for access to their patients and also to thank the consultant paediatricians for their help in assessing neonatal maturity.

\section{References}

Adams, F. H., Fujiwara, T., Emmanouilides, G., and Scudder, A. (1965). Fournal of Pediatrics, 66, 357.

Bartlett, G. R. (1959). Fournal of Biological Chemistry, 234, 466.

Bhagwanani, S. G., Fahmy, D., and Turnbull, A. C. (1972). Lancet, 1, 159, 160.

Biggs, J. S. G., Gaffney, T. J., and McGeary, H. M. (1973). Fournal of Obstetrics and Gynaecology of the British Commonwealth, 80, 125.

Bligh, E. G., and Dyer, W. J. (1959). Canadian fournal of Biochemistry and Physiology, 37, 911 .

Brumley, G. W., Hodson, W. A., and Avery, M. E. (1967). Pediatrics, 40, 13.

Charles, D., and Jacoby, H. E. (1966). American fournal of Obstetrics and Gynecology, 95, 266.

Gadd, R. L. (1966). Fournal of Obstetrics and Gynaecology of the British Commonwealth, 73, 11.

Gluck, L., et al. (1971). American fournal of Obstetrics and Gynecology, 109, 440.

Gluck, L., Kulovich, M. V., Eidelman, A. I., Cordero, L., and Khazin, A. F. (1972). Pediatric Research, 6, 81.

Nelson, G. H. (1970). American fournal of Obstetrics and Gynecology, 105, 1072 .

Skipski, V. P., Peterson, R. F., Sanders, J., and Barclay, M. (1963). fournal of Lipid Research, 4, 227.

\title{
Effect of Different Periods of Fasting on Oral Glucose Tolerance
}

\author{
C. H. WALSH, J. O'REGAN, D. J O'SULLIVAN
}

British Medical Fournal, 1973, 2, 691-693

\section{Summary}

The effect of different periods of fasting on oral glucose tolerance was investigated in 33 subjects. It was found that glucose tolerance deteriorated as the fasting period became shorter. This effect was seen almost exclusively in subjects over 40 years of age. Only the fasting blood sugar was affected by the duration of the pretest fast in younger subjects.

\section{Introduction}

The oral glucose tolerance test was introduced by Hamman and Hirschman (1917), after some preliminary work by Jacobsen (1913) and Hopkins (1915). Though its value in the definitive diagnosis of diabetes mellitus is unchallenged, it has in recent years been under close and critical scrutiny (McDonald et al., 1965; Klimt et al., 1969). It is only to be expected, however, that years of use should expose some of its shortcomings. These have recently been comprehensively reviewed by the Committee on Statistics of the American Diabetes Association (Klimt et al., 1969). Any study that will help to reduce the multiplicity of variables associated with the test is likely to be of much value. Little information and considerable difference of opinion exist about the significance of the length of the pretest fasting period. Because of this we have undertaken a study of the influence of various periods of fasting on glucose tolerance.

Department of Medicine, St. Finbarr's Hospital, Cork, and University College, Cork, Eire

C. H. WALSH, M.B., M.R.C.P., Medical Registrar (Present address: General Hospital, Birmingham)

J. O'REGAN, M.B., B.A.O., Senior House Office

D. J. O'SULLIVAN, M.D., F.R.C.P., Professor of Medicine

\section{Subjects and Methods}

Thirty-three subjects were investigated, 17 men and 16 women. Their ages ranged from 18 to 84 years (mean age 46 years). They comprised medical students and staff from the department of medicine together with long-stay occupants of an institution for the homeless. Several of the latter were employed in domestic duties. All subjects were clinically healthy and ambulant, apart from one who had suffered a cerebrovascular accident several years previously.

All were on an unrestricted diet and none was on any agents known to interfere with glucose tolerance. Each subject had three glucose tolerance tests $(50 \mathrm{~g}$ glucose) within a period of two weeks. Before each test they fasted for 12 , eight, or four hours in random fashion. The last meal was taken immediately before the start of the fasting period, and was constant in composition, containing about $30 \mathrm{~g}$ carbohydrate in tea, bread, butter, and jam. The tests were carried out under strictly standardized conditions and all began between 0900 and 0930 hours.

\section{Results}

The results for the 33 subjects are given in table I and fig. 1 .

TABLE I-Mean ( \pm S.D. of Mean) Blood Sugar Values $(\mathrm{mg} / 100 \mathrm{ml})$ for Three Glucose Tolerance Tests in 33 Subjects

\begin{tabular}{|c|c|c|c|c|c|c|c|}
\hline \multirow{2}{*}{\multicolumn{2}{|c|}{ Pretest Fast }} & & \multicolumn{5}{|c|}{ Time (Minutes) } \\
\hline & & & 0 & 30 & 60 & 90 & 120 \\
\hline $\begin{array}{r}12 \text { hours } \\
8 \text { hours } \\
4 \text { hours }\end{array}$ & & $\begin{array}{l}. \\
\cdots\end{array}$ & $\begin{array}{l}73 \pm 9 \\
81 \pm 12 \\
77 \pm 12\end{array}$ & $\begin{array}{l}108 \pm 21 \\
118 \pm 29 \\
124 \pm 31\end{array}$ & $\begin{array}{l}103 \pm 33 \\
102 \pm 33 \\
113 \pm 45\end{array}$ & $\begin{array}{l}83 \pm 33 \\
93 \pm 40 \\
96 \pm 40\end{array}$ & $\begin{array}{l}79 \pm 27 \\
92 \pm 38 \\
88 \pm 35\end{array}$ \\
\hline
\end{tabular}

The mean blood sugar values after the eight-hour fast are significantly greater than those after the 12-hour fast at fasting 


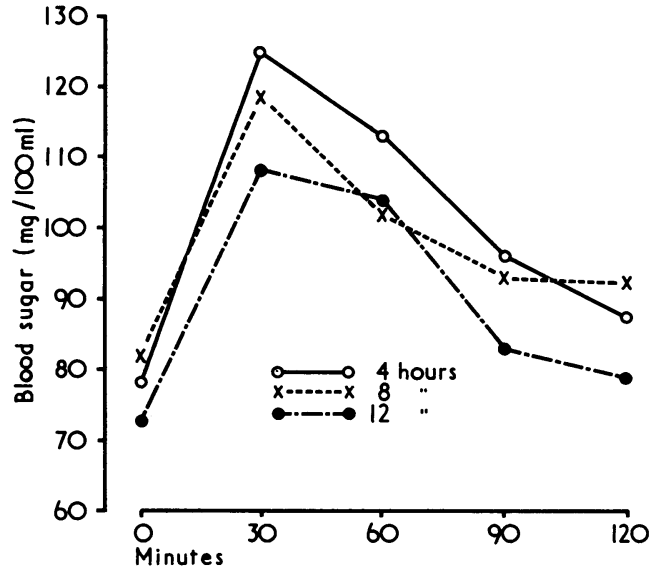

FIG. 1-Mean values for three glucose tolerance tests in 33 subjects.

TABLB II-Mean ( \pm S.D. of Mean) Blood Sugar Values $(\mathrm{mg} / 100 \mathrm{ml})$ for Three Glucose Tolerance Tests in 18 Subjects over 40 Years of Age

\begin{tabular}{|c|c|c|c|c|c|c|c|}
\hline \multirow{2}{*}{\multicolumn{3}{|c|}{ Pretest Fast }} & \multicolumn{5}{|c|}{ Time (Minutes) } \\
\hline & & & \multirow{2}{*}{$\begin{array}{c}0 \\
75 \pm 8 \\
84 \pm 10 \\
82 \pm 10\end{array}$} & \multirow{2}{*}{$\begin{array}{c}30 \\
115 \pm 19 \\
127 \pm 30 \\
140 \pm 27\end{array}$} & \multirow{2}{*}{$\begin{array}{c}60 \\
125 \pm 26 \\
123 \pm 26 \\
144 \pm 38\end{array}$} & \multirow{2}{*}{$\begin{array}{c}90 \\
98 \pm 36 \\
113 \pm 43 \\
123 \pm 33\end{array}$} & \multirow{2}{*}{$\begin{array}{r}120 \\
91 \pm 29 \\
113 \pm 38 \\
105 \pm 39\end{array}$} \\
\hline $\begin{array}{r}12 \text { hours } \\
8 \text { hours } \\
4 \text { hours }\end{array}$ & $\ddot{x}$ & $\ddot{m}$ & & & & & \\
\hline
\end{tabular}

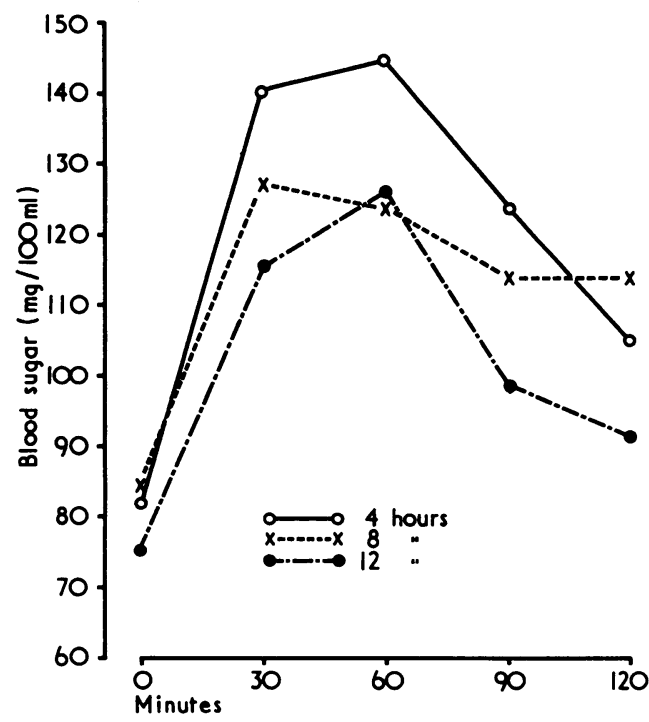

FIG. 2-Mean values for three glucose tolerance tests in 18 subjects over 40 years of age.

$(P=0.005), 30 \mathrm{~min}(P=0.05)$, and $120 \mathrm{~min}(P=0.05)$. After the four-hour fast the mean blood sugar values are greater than those after the 12-hour fast at all points-fasting $(P=0.05), 30 \mathrm{~min}(P=0.005), 60 \mathrm{~min}(P=0.05), 90 \mathrm{~min}$ $(P=0.005)$, and $120 \mathrm{~min}(P=0.005)$. The mean values after the four-hour fast exceed those after the eight-hour fast at $60 \min (P=0.025)$.

The effect of age was examined by dividing the subjects into those aged over $\mathbf{4 0}$ and those aged $\mathbf{4 0}$ and under. The results for the group over $\mathbf{4 0}$ years are shown in table II and fig. 2. The mean values after the eight-hour fast exceed those after the 12-hour fast at fasting $(P=0.005), 90 \mathrm{~min}(P=0.01)$, and
$120 \min (P=0.005)$. The mean values after the four-hour fast exceed those after the 12-hour fast at all points-fasting $(P=0.0005), 30 \mathrm{~min}(P=0.0005), 60 \mathrm{~min}(P=0.005)$, $90 \mathrm{~min}(P=0.0005)$, and $120 \mathrm{~min}(P=0.025)$. The values after four hours exceed those after eight hours at $60 \mathrm{~min}$ $(P=0.01)$

In the group aged 40 or under the fasting level after the eight-hour fast exceeds that after the 12-hour fast $(P=0.025)$. None of the other values differ significantly (table III).

TABLE III-Mean ( \pm S.D. of Mean) Blood Sugar Values (mg/100 ml) for Three Glucose Tolerance Tests in 15 Subjects Aged 40 Years and Under

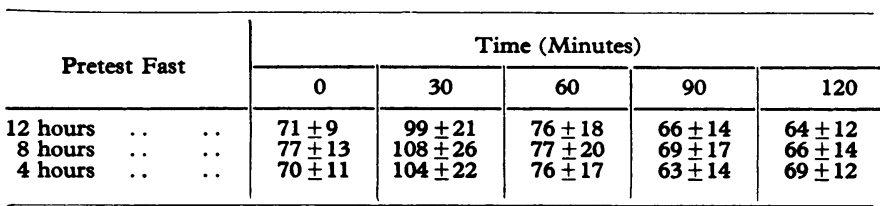

\section{Discussion}

The major drawback of the oral glucose tolerance test is the difficulty in interpreting the results. This problem is contributed to by a number of factors-the arbitrary dividing line between normal and abnormal, the increase with age of abnormal results (Report of Working Party, 1963; Hayner et al., 1965; Butterfield, 1966), and the lack of reproducibility of individual results (McDonald et al., 1965). It seems that at present little can be done about most of these factors. The Committee on Statistics of the American Diabetes Association (Klimt et al., 1969), however, pointed out that there exists a multiplicity of remediable variables associated with the glucose tolerance test which can undermine its usefulness. It is hoped that the publicity given to these variables will help in their elimination. One factor, however, that continues to receive little attention is the pretest fasting period. Considerable divergence of opinion exists as to the recommended length of the fast, probably because there are few scientific data which indicate that it is of any significance. The British Diabetic Association (FitzGerald and Keen, 1964) is specific in its recommendation of a 12-hour fasting period. Klimt et al. (1969) recommended a fasting period of not less than eight hours and not longer than 16 hours. Other authorities perform glucose tolerance tests after an "overnight fast" (Fajans, 1971) or in the "fasting state" (Marble, 1971). Obviously a considerable variation could exist in the latter two cases, depending on the time of the last meal and the time of starting the test.

The purpose of this study was to determine whether the length of the pretest fast influenced glucose tolerance. It was felt that if the results showed that the fasting period under investigation failed to influence glucose tolerance, it would then be possible to recommend that outpatients could have this investigation in the afternoon or evening after a four-hour fast. This might not only be of more diagnostic value (Jarrett and Keen, 1970) but it would minimize the inconvenience to. the patient of a long fast and absence from work.

The results of the study, however, show that the duration of the pretest fast does have a considerable influence on glucose tolerance. In the whole group of subjects studied, glucose tolerance was better after a 12-hour fast than after an eight- or four-hour fast. It seems, however, that the age of the subjects is an important factor. In the young subjects the values after the glucose challenge in the three tests are not significantly different. In those over 40 year of age, however, glucose tolerance deteriorates as the length of the fasting period becomes shorter. These findings do not support the observations of Hayner et al. (1965). They found that blood sugar levels one hour after a glucose load were on average $25 \mathrm{mg} / 100 \mathrm{ml}$ lower in subjects who had eaten within 4 hours than in subject who had not eaten for a longer period. It may be that large population surveys do not 
give similar results to studies of small groups (Jarrett and Keen, 1970). It is also worthy of note that no diurnal variation in glucose tolerance was observed in the study of Hayner et al. (1965) in contrast to other reports (Roberts, 1964; Bowen and Reeves, 1967; Jarrett and Keen, 1969).

In view of the results of this investigation it is pertinent to mention that in a number of important studies of glucose tolerance in recent years the pretest fasting period was not standardized (Roberts, 1964; McDonald et al., 1965; Bowen and Reeves, 1967; Jarrett and Keen, 1969, 1970). This does not necessarily imply that the conclusions drawn from these studies are invalid. It does, however, indicate that in future studies of glucose tolerance more attention must be given to standardization of the fasting period if practical conclusions are to be derived from them.

When a glucose tolerance test is arranged, it is important that its objective should be borne in mind. If the test is carried out for a reason other than the diagnosis of diabetes, an arbitrary pretest fasting period can be chosen. This situation would obtain for example if the test is being used in a comparative study to evaluate the influence of some factor on glucose tolerance. Needless to say, the pretest fasting period should be constant, even though arbitrary.

If, on the other hand, the glucose tolerance test is being used for the diagnosis of diabetes, a standard fasting period is desirable. Otherwise it is not possible, on the basis of the results presented here, to lay down criteria of normality and abnormality. Three of the subjects over 40 years of age who were studied had diabetic glucose tolerance tests according to the criteria of the British Diabetic Association (FitzGerald and Keen, 1964). If, however, the same criteria were used with the single exception that the fasting period was eight rather than 12 hours, two further subjects would have been classified as diabetic. This suggests that one is not justified in diagnosing diabetes according to the criteria of the British Diabetic Association, or indeed according to the criteria of any scientific group, if the recom- mended test procedure in relation to fasting is not adhered to (Jarrett et al., 1972).

The results of this study suggest that the length of the pretest fast has a significant effect on the result of oral glucose tolerance tests. Strict adherence to the recommendations of the British Diabetic Association (FitzGerald and Keen, 1964) when performing oral glucose tolerance tests for diagnostic purposes, is desirable. The results reported here also suggest that other centres which allow a wide range of pretest fasting (Klimt et al., 1969) may need to review this aspect of the procedure. One of the factors which may contribute to the lack of reproducibility of oral glucose tolerance tests is the failure to ensure constant pretest fasting periods.

We acknowledge the financial support of the Medical Research Council of Ireland, and the statistical help of Dr. T. O'Donovan.

\section{References}

Bowen, A. J., and Reeves, R. L. (1967). Archives of Internal Medicine, 119, 261 .

Butterfield, W. J. H. (1966). In Diabetes Mellitus, ed. L. J. P. Duncan, p. 149. London, University Press.

Fajans, S. S. (1971). Medical Clinics of North America, 55, 793.

FitzGerald, M. G., and Keen, H. (1964). British Medical fournal, 1, 1568. Hamman, L., and Hirschman, I. I. (1917). Archives of Internal Medicine, 20, 761 .

Hayner, N. S., Kjelsberg, M. O., Epstein, F. H., and Francis, T., jun. (1965). Diabetes, 14, 413.

Hopkins, A. H. (1915). American Fournal of the Medical Sciences, 102, 254. Humphrey, C. S., Dykes, J. R. W., and Johnston, D. (1972). British Medical fournal, 4, 393.

Jacobsen, H. (1913). Biochemische Zeitschrift, 56, 471.

Jarrett, R. J., and Keen, H. (1969). British Medical fournal, 2, 341.

Jarrett, R. J., and Keen, H. (1970). British Medical fournal, 4, 334.

Jarrett, R. J., Baker, I. A., Keen, H., and Oakley, N. W. (1972). British Medical fournal, 1, 199.

Klimt, C. R., et al. (1969). Diabetes, 18, 299.

Marble, A. (1971). Foslin's Diabetes Mellitus, ed. A. Marble, P. White, R. F. Bradley, and L. P. Krall, p. 203. Philadelphia, Lea and Febiger. McDonald, G. W., Fisher, G. F., and Burnham, C. (1965). Diabetes, 14, 573. Report of Working Party appointed by College of General Practitioners (1963). British Medical fournal, 2, 655.

Roberts, H. (1964). Fournal of the American Geriatrics Society, 12, 423.

\title{
Spontaneous Periodic Hypothermia: Diencephalic Epilepsy
}

\author{
R. H. FOX, D. C. WILKINS, J. A. BELL, R. D. BRADLEY, N. L. BROWSE, W. I. CRANSTON, \\ T. H. FOLEY, E. D. GILBY, ANN HEBDEN, B. S. JENKINS, M. D. RAWLINS
}

British Medical fournal, 1973, 2, 693-695

\section{Summary}

The case of a patient with episodic hypothermia and profuse sweating believed to be due to diencephalic epilepsy is reported. Despite intensive investigations no

National Institute for Medical Research, London NW3 6RB

R. H. FOX, M.B., M.R.C.P., Member of Scientific Staff

D. C. WILKINS, M.B., CH.B., Scientist

St. Thomas's Hospital and Medical School, London S.E.1

J. A. BELL, M.B., M.R.C.P., Medical Registrar

R. D. BRADLEY, M.B., B.SC., Consultant Clinical Physiologist

N. L. BROWSE, M.D., F.R.C.S., Professor of Vascular Surgery

W. I. CRANSTON, M.D., F.R.C.P., Professor of Medicine

T. H. FOLEY, M.D., M.R.C.P., Lecturer in Medicine

E. D. GILBY, M.R.C.P., Registrar in Endocrinology

ANN HEBDEN, Chief Technician, E.E.G. Department

B. S. JENKINS, M.B., M.R.C.P., Senior Lecturer in Clinical Physiology

M. D. RAWLINS, B.SC., M.R.C.P., Lecturer in Medicine other manifestations of hypothalamic dysfunction were found. Conventional antiepileptic drugs were without efiect but the patient was successfully treated by total sympathectomy.

\section{Introduction}

Spontaneous periodic hypothermia associated with profound sweating is a rare condition involving a severe disturbance of thermoregulatory control. We report the investigation and successful management of such a case which showed a number of distinctive features.

\section{Present Study}

CASE REPORT

A 49-year-old veterinary assistant was admitted to the Hospital for Tropical Diseases in October 1969 under the care of Professor A. W. 